\title{
Pengaruh Menstruasi terhadap Akne Vulgaris
}

\author{
Lusiane M. Hartono, ${ }^{1}$ Marlyn G. Kapantow, ${ }^{2}$ Tara S. Kairupan ${ }^{2}$ \\ ${ }^{1}$ Program Studi Pendidikan Dokter Fakultas Kedokteran Universitas Sam Ratulangi, Manado, \\ Indonesia \\ ${ }^{2}$ Bagian Ilmu Kesehatan Kulit dan Kelamin Fakultas Kedokteran Universitas Sam Ratulangi, \\ Manado, Indonesia \\ Email: hartonoml@gmail.com
}

\begin{abstract}
Acne vulgaris is a common inflammatory condition of pilosebaceous follicles that affects $85-100 \%$ of the human population. Patients usually complain of the appearance of acne vulagaris on the predilection areas such as face and neck (99\%), back (60\%), chest, shoulders and upper arms $(15 \%)$. One of the factors that influence or trigger acne vulgaris is hormonal factor. During menstruation there is an increase and hormonal changes that can trigger acne. This study was aimed to determine the effect of menstruation on acne vulgaris. This was a literature review study using three databases named PubMed, ClinicalKey and Google Scholar. Keywords used were "Menstruasi" DAN "Akne Vulgaris" (Indonesia), and "Menstruation" AND "Acne Vulgaris" (English). In this study, there were 12 literatures that match the inclusion and exclusion criteria. The result was dominated by samples stating that there was a connection between menstruation and the appearance of acne vulgaris. The effect of hormonal instability during menstruation was one of the causes of acne vulgaris in women, which showed the effect of menstruation on the emergence of acne vulgaris, mostly during pre-menstruation. In conclusion, menstruation influences the occurrence and the severity of acne vulgaris.
\end{abstract}

Keywords: menstruation, acne vulgaris

\begin{abstract}
Abstrak: Akne vulgaris (AV) atau jerawat merupakan suatu kondisi inflamasi umum pada folikel pilosebasea yang dialami oleh $85-100 \%$ populasi manusia. Penderita biasanya mengeluh kemunculan AV pada predileksi wajah dan leher (99\%), punggung (60\%), dada (15\%) bahu, dan lengan bagian atas. Faktor yang memengaruhi atau mencetuskan akne vulgaris salah satunya ialah faktor hormonal. Saat menstruasi terjadi peningkatan dan perubahan hormon yang dapat memicu akne. Penelitian ini bertujuan untuk mengetahui pengaruh menstruasi terhadap akne vulgaris. Penelitian ini berbentuk literature review. Pencarian data menggunakan tiga database yaitu PubMed, ClinicalKey dan Google Scholar. Kata kunci yang digunakan "Menstruasi" DAN "Akne Vulgaris" (Bahasa Indonesia) serta "Menstuation" AND "Acne Vulgaris" (Bahasa Inggris). Pada penelitian ini didapatkan 12 literatur yang sesuai dengan kriteria inklusi dan ekslusi. Hasil penelitian didominasi oleh sampel yang menyatakan adanya pengaruh antara menstruasi dengan munculnya AV. Pengaruh ketidakstabilan hormon (estrogen dan progesteron) saat menstruasi merupakan salah satu penyebab munculnya akne vulgaris pada perempuan yang menunjukan adanya pengaruh dari menstruasi terhadap kemunculan $\mathrm{AV}$, terlebih pada saat pre-menstruasi. Simpulan penelitian ini ialah menstruasi memengaruhi kemunculan dan keparahan akne vulgaris.

Kata kunci: menstruasi, akne vulgaris
\end{abstract}

\section{PENDAHULUAN}

Akne vulgaris merupakan peradangan kronis folikel polisebasea yang dialami oleh 85-100\% populasi manusia. Bahkan menurut Kligman, tidak ada seorangpun yang sama sekali tidak pernah menderita akne. Manifestasi klinisnya berupa komedo, papul, pustul, nodus serta kista, dengan tempat predileksi akne vulgaris di wajah dan leher (99\%), punggung (60\%), serta dada, 
bahu dan lengan atas (15\%). Akne vulgaris umumnya dimulai usia 12-15 tahun, puncak tingkat keparahannya pada usia 17-21 tahun dan akne vulgaris adalah penyakit terbanyak pada remaja usia $15-18$ tahun. ${ }^{1}$

Di Asia, beberapa data menunjukan prevalensi tinggi, dari survei yang ada di Kawasan Asia Tenggara terdapat 40-80\% kasus. ${ }^{3}$ Menurut penelitian Mizwar M, dkk di RSUP Prof. RD Kandou Manado periode 2009-2011 menunjukkan terdapat 121 pasien AV yang didominasi oleh wanita sebanyak 75 pasien. $^{2}$

Hingga saat ini belum dapat disimpulkan mengenai etiologi secara pasti. Namun, terdapat beberapa faktor etiologi dari AV yang diduga berperan, yang dibagi atas intrinsik dan ekstrinsik seperti: genetik, faktor hormonal, diet/makanan, iklim, suhu, kelembapan, kosmetik dan penggunaan obat obatan, infeksi dan trauma, kondisi kulit, serta pengaruh lingkungan dan pekerjaan. ${ }^{1}$

Menstruasi adalah perdarahan periodik dari uterus akibat terlepasnya lapisan endometrium uterus yang rutin dialami tiap bulannya oleh wanita normal. ${ }^{3}$ Siklus menstruasi mengacu pada perubahan aktivitas ovarium dan endometrium yang juga berperan dalam proses reproduksi. ${ }^{4}$

Penyebab AV salah satunya ialah peran hormon berupa androgen, estrogen, dan progesteron. Pada wanita, sangat sering dikaitkan antara munculnya AV dengan siklus menstruasi. Hal ini juga didukung oleh fakta bahwa AV sering terjadi akibat rendahnya hormon estrogen dan progesteron selama beberapa siklus menstruasi pertama. Tercatat bahwa hormon progesteron dianggap bertanggungjawab atas aktivitas rangsangan kelenjar sebasea pada wanita. $^{5}$

Berdasarkan kaitan antara terjadinya akne vulgaris, perubahan hormon pada wanita, dan menstruasi maka penulis tertarik untuk melakukan studi kepustakaan yang membahas, menelaah, dan merangkum informasi dari berbagai sumber mengenai pengaruh menstruasi terhadap AV.

\section{METODE PENELITIAN}

Penelitian ini merupakan suatu literature review dengan menggunakan tiga database, yakni PubMed, ClinicalKey, dan Google Scholar dan kata kunci "Menstruasi" DAN "Akne Vulgaris" (Bahasa Indonesia) dan "Menstruation" AND "Acne Vulgaris" (Bahasa Inggris). Penelitian ini menggunakan data terbitan 10 tahun terakhir (20112020) dengan ketersediaan full text.

\section{HASIL PENELITIAN}

Setelah diseleksi berdasarkan kriteria inklusi dan ekslusi penelitian, didapatkan 12 literatur yang sesuai. Dari kedua belas literatur, terdapat 10 penelitian crosssectional dan 2 penelitian cohort. Hasil penelitian dari masing-masing literatur diuraikan pada Tabel 1.

Tabel 1. Hasil kajian literatur yang digunakan dalam penelitian

\begin{tabular}{|c|c|c|c|c|}
\hline No. & Peneliti, judul dan tahun & $\begin{array}{l}\text { Jumlah } \\
\text { sampel }\end{array}$ & $\begin{array}{c}\text { Desain } \\
\text { penelitian }\end{array}$ & Hasil \\
\hline 1. & $\begin{array}{l}\text { Widiawaty et al, } 2019 .^{6} \\
\text { Pengaruh fase menstruasi } \\
\text { terhadap derajat akne vulgaris } \\
\text { Mahasiswi Fakultas } \\
\text { Kedokteran Universitas Riau. }\end{array}$ & $\mathrm{P}=89$ & $\begin{array}{l}\text { Cross sectional } \\
\text { Uji statistik } \\
\text { Marginal } \\
\text { Homogeneity }\end{array}$ & $\begin{array}{l}\text { Terdapat hubungan bermakna antara } \\
\text { fase menstruasi dengan derajat AV dan } \\
\text { terdapat perbedaan rerata lesi inflamasi } \\
\text { pre menstruasi dan post menstruasi. } \\
\mathrm{p}=0,001 \text {. }\end{array}$ \\
\hline 2. & $\begin{array}{l}\text { Siregar et al, } 2016 .^{7} \text { Hubung- } \\
\text { an antara kelainan siklus } \\
\text { menstruasi dengan kejadian } \\
\text { akne vulgaris pada santriwati } \\
\text { SMA Islam Terpadu Nur } \\
\text { Hidayah Kartasura. }\end{array}$ & $\mathrm{P}=55$ & $\begin{array}{l}\text { Cross-sectional } \\
\text { Uji statistik Chi } \\
\text { square }\end{array}$ & $\begin{array}{l}\text { Tidak terdapat hubungan yang signifi- } \\
\text { kan antara kelainan siklus menstruasi } \\
\text { dengan kejadian AV pada santriwati } \\
\text { SMA Islam Terpadu Nur Hidayah } \\
\text { Kartasura. } p=0,103\end{array}$ \\
\hline 3. & $\begin{array}{l}\text { Elmiyati dan Fadhil, } 2019 .{ }^{8} \\
\text { Hubungan waktu menstruasi } \\
\text { dengan kejadian akne }\end{array}$ & $P=67$ & $\begin{array}{l}\text { Cross-sectional } \\
\text { Uji statistik Chi } \\
\text { square }\end{array}$ & $\begin{array}{l}\text { Dapat disimpulkan bahwa terdapat } \\
\text { hubungan waktu pre menstruasi dengan } \\
\text { kejadian akne dengan analisis bivariate }\end{array}$ \\
\hline
\end{tabular}


vulgaris pada mahasiswi kedokteran Abulyatama Aceh.

4. Indrawan dan Kusumastuti, 2013. ${ }^{9}$ Hubungan asupan lemak jenuh dengan kejadian acne vulgaris.

2013

5. Purwaningdyah dan Jusuf, 2013. ${ }^{10}$ Profil penderita akne vulgaris pada siswa siswi di SMA Shafiyyatul Amaliyyah Medan.

6. Geller et al, 2014. ${ }^{11}$ Perimenstrual flare of adult acne.

7. Yazmalar et al, 2016. ${ }^{12}$ High frequency of fibromyalgia in patients with acne vulgaris.

8. George dan Sridharan, 2018. ${ }^{13}$. Factors aggravating or precipitating acne in Indian adults: A hospitalbased study of 110 cases.

9. Dae et al, 2011. ${ }^{14}$

A multicenter epidemiological study of acne vulgaris in Korea

10. Gonçalves et al, 2012. ${ }^{15}$ The prevalence of acne among a group of Portuguese medical students.

11. Ayudianti dan Indramaya, 2014. ${ }^{16}$

Studi Retrospektif: Faktor pencetus Akne Vulgaris

12. Astuti, 2011. ${ }^{17}$

Hubungan antara menstruasi dengan angka kejadian akne vulgaris pada remaja.

$\begin{array}{ll}\mathrm{P}=60 & \text { Cross-sectional } \\ & \text { Uji statistik Chi } \\ \text { square }\end{array}$

$\begin{array}{ll}\mathrm{L}=58 & \text { Cross }- \text { sectional } \\ \mathrm{P}=42 & \text { Uji statistik } \\ & \text { Consecutive } \\ & \text { sampling }\end{array}$

$\mathrm{P}=105 \quad$ Cross-sectional

Uji statistik Unpaired t-test
$\mathrm{L}=28 \quad$ Cross-sectional
$\mathrm{P}=60 \quad$ Uji statistik $C h i$ square
$\mathrm{L}=21 \quad$ Cross-sectional
$\mathrm{P}=89 \quad$ Uji statistik $C h i$ square

$\begin{array}{ll}\mathrm{L}=480 & \begin{array}{l}\text { Cohort study } \\ \mathrm{P}=756\end{array} \\ & \begin{array}{l}\text { Tabulated in } \\ \text { Microsoft } \text { Excel } \\ \text { worksheet and } a \\ \text { computer-based } \\ \text { analysis data } \\ \text { using SPSS } \\ \text { Version } 24\end{array} \\ \mathrm{~L}=31 & \begin{array}{l}\text { Cohort study } \\ \mathrm{P}=67\end{array} \\ & \text { Uji statistik Chi } \\ & \text { Square }\end{array}$

$\mathrm{L}=711 \quad$ Cross-sectional $\mathrm{P}=2737 \quad$ Studi retrosepktif terhadap rekam medik.

$\begin{array}{ll}\mathrm{P}=60 & \text { Cross-sectional } \\ & \text { Uji statistik Chi } \\ \text { square }\end{array}$

chi square $\mathrm{p}=, 002 \quad(\mathrm{p}<0,05) . \quad$ Dan terdapat hubungan waktu saat menstruasi dengan kejadian akne dengan analis bivariate chi square $\mathrm{p}=$ ,005 ( $\mathrm{p}<0,05)$.

Berdasarkan hasil wawancara sebagian besar subjek $(41,7 \%)$ menyatakan timbulnya acne vulgaris sewaktuwaktu. Pada sebagian besar siswi yang menderita acne terdapat Faktor menstruasi berpengaruh pada kejadian acne vulgaris $\mathrm{p}=0,003$.

Penderita akne vulgaris di SMA Shafiyyatul Amaliyyah Medan mayoritas berjenis kelamin perempuan menderita akne vulgaris pada setelah dan sebelum menstruasi (15\%), hal ini menunjukkan keterkaitan.

Terdapat hubungan antara kejadian menstruasi dengan kemunculan AV, dan $56 \%$ responden menyatakan AV memburuk pada seminggu sebelum menstruasi atau premenstruasi.

Nyeri terkait fibromyalgia, gangguan tidur, kecemasan, dan gangguan siklus menstruasi secara signifikan lebih sering terjadi pada pasien dengan acne vulgaris daripada kontrol.

$78,7 \%$ responden mengalami akne pramenstruasi dimana $60 \%$ memiliki akne persisten dan $40 \%$ memiliki akne onset lambat, dan perbedaan ini ditemukan signifikan secara statistik.

Studi ini menunjukkan yang memperburuk AV adalah stres, kurang tidur, merokok, konsumsi alkohol, dan menstruasi. Seperti jenis kelamin, usia saat onset, riwayat Hubungan yang signifikan ditemukan antara klinis, epidemiologi, dan karakteristik perilaku penderita akne menurut beberapa faktor.

Prevalensi AV tidak berhubungan secara signifikan dengan jenis kelamin, riwayat akne dalam keluarga, rambut berminyak, kebiasaan merokok atau adanya akne Keteraturan siklus menstruasi tidak berhubungan dengan adanya AV di antara 67 wanita.

Pengaruh hormonal pada pasien perempuan $89 \%$. Faktor hormonal pada pasien perempuan berhubungan dengan siklus menstruasi. Pasien banyak mengeluhkan bahwa AV muncul sesaat sebelum atau sesudah menstruasi.

Hubungan antara menstruasi dengan angka kejadian akne vulgaris pada remaja. Kejadian akne vulgaris paling banyak ditemukan sebelum menstruasi $(41,7 \%)$. 


\section{BAHASAN}

Berdasarkan hasil kajian literaturliteratur penelitian ini, didapatkan dominasi adanya pengaruh atau hubungan antara menstruasi dengan AV. Penelitian Widiawaty et $\mathrm{al}^{6}$ melaporkan bahwa pada uji marginal homogeneity didapatkan hubungan bermakna antara fase menstruasi dengan derajat AV dengan nilai $\mathrm{p}=0,001$. Elmiyati dan Fadhil $^{8}$ mendapatkan bahwa tingkat kejadian AV sebelum waktu menstruasi sebanyak 40 responden $(59,7 \%)$ dan kejadian AV sesudah menstruasi sebanyak 13 responden $(19,4 \%)$. Terdapat hubungan waktu pre menstruasi dengan kejadian AV yang diuji dengan analisis bivariat chi square, $\mathrm{p}=0,002 \quad(\mathrm{p}<0,05)$. Juga terdapat hubungan waktu saat menstruasi dengan kejadian AV melalui analisis bivariat chi square, $\mathrm{p}=0,005(\mathrm{p}<0,05)$.

Penelitian Indrawan dan Kusumastuti ${ }^{9}$ melaporkan bahwa kejadian AV paling banyak ditemukan pada usia 16-17 tahun $(51,7 \%)$. Asupan lemak jenuh pada responden sebagian besar tergolong lebih dari cukup $(50,0 \%)$. Berdasarkan hasil wawancara sebagian besar subjek $(41,7 \%)$ menyatakan timbulnya AV terjadi sewaktu-waktu. Faktor menstruasi berpengaruh pada kejadian AV p=0,003,

Pada penelitian oleh Purwaningdyah dan Jusuf ${ }^{10}$ didapatkan bahwa mayoritas penderita AV berjenis kelamin laki-laki (58\%), usia 17 tahun (41\%), memiliki orang tua menderita AV (41\%), menderita AV saat sebelum dan sesudah menstruasi (15\%). Selain itu, mengonsumsi kacang kacangan (64\%), akibat dari panas $(70 \%)$, faktor psikis $(90 \%)$ dan kosmetik (18\%) dapat memicu terjadinya AV.

Penelitian Geller et al ${ }^{11}$ mendapatkan bahwa mayoritas responden dengan AV premenstruasi melaporkan timbulnya AV antara usia 12 dan 18 tahun. Terdapat $65 \%$ responden yang melaporkan bahwa gejala AV lebih memburuk dengan menstruasi. Dari responden yang melaporkan gejala AV pre-menstruasi, terdapat $56 \%$ yang melaporkan gejala yang memburuk dalam seminggu sebelum menstruasi, $17 \%$ melaporkan gejala yang memburuk selama menstruasi, $3 \%$ melaporkan gejala yang memburuk setelah menstruasi mereka, dan $24 \%$ melaporkan gejala memburuk sepanjang siklus.

Yazmalar et $\mathrm{al}^{12}$ menyatakan bahwa nyeri terkait fibromialgia, gangguan tidur, kecemasan, dan gangguan siklus menstruasi secara bermakna lebih sering terjadi pada pasien dengan AV daripada kontrol.

Pada penelitian George dan Sridharan ${ }^{13}$ didapatkan bahwa makanan dan kosmetik dikaitkan dengan eksaserbasi sebesar 47,3\% dan $40 \%$. Sementara itu $32,7 \%$ pasien mengalami eksaserbasi selama stres, $26,4 \%$ setelah paparan sinar matahari dan $23,6 \%$ setelah berkeringat. Sekitar $48 \%$ pasien memiliki riwayat AV. Sebagian besar pasien wanita pernah kambuh AV saat pre menstruasi, yang jauh lebih umum di antara pasien dengan AV yang persisten.

Pada penelitian Dae et al $^{14}$ dilaporkan bahwa AV pertama kali berkembang paling sering di dahi dan pipi, meskipun pipi lebih banyak sangat terpengaruh. Hubungan bermakna ditemukan antara klinis, epidemiologi, dan karakteristik perilaku penderita akne menurut beberapa faktor, seperti jenis kelamin, usia saat onset, riwayat pengobatan sebelumnya, dan riwayat keluarga. Studi ini menunjukkan yang memperburuk AV ialah stres, kurang tidur, merokok, konsumsi alkohol, dan menstruasi.

Astuti $^{17}$ dalam penelitiannnya mendapatkan bahwa kejadian AV paling banyak ditemukan pada waktu sebelum menstruasi $(41,7 \%)$. Usia terbanyak yang menderita AV ialah 17 tahun (53,3\%), riwayat keluarga kurang memengaruhi AV $(41,7 \%)$ dengan riwayat AV ditemukan paling banyak pada ibu (64\%), kosmetik berpengaruh pada AV (86,7\%), terapi AV masih rendah $(23,3 \%)$ dan bentuk obat paling banyak yaitu obat oles $(93,3 \%)$, perilaku membersihkan wajah secara teratur (75\%), faktor stres berpengaruh pada AV (55\%), jenis makanan yang berpengaruh pada AV paling banyak yaitu kacangkacangan (60\%). Terdapat hubungan antara menstruasi dengan angka kejadian AV pada remaja $(\mathrm{p}=0,004)$.

Pada penelitian Ayudianti dan Indra- 
maya ${ }^{16}$ dilaporkan bahwa faktor pencetus timbulnya AV pada pasien di Divisi Kosmetik Medik URJ Kesehatan Kulit dan Kelamin RSUD Dr. Soetomo Surabaya periode tahun 2008-2010 terbanyak akibat faktor hormonal yaitu 1919 pasien $(55,6 \%)$. Hal itu mungkin disebabkan karena pada pasien wanita kekambuhan AV lebih sering terjadi terutama jika dihubungkan dengan siklus menstruasi selain kesadaran tentang pentingnya menjaga penampilan lebih tinggi dibandingkan dengan pria. Pasien pria cenderung terlambat untuk mencari pengobatan AV dan lebih memilih untuk membiarkan keluhan kemudian baru datang berobat jika kondisi sudah parah. Faktor pencetus terbanyak pada pasien pria idalah makanan $(23,2 \%)$ dan stres $(23,9 \%)$, sedangkan pada pasien wanita ialah hormonal $(89 \%)$ dan kosmetik $(89,1 \%)$. Faktor hormonal pada pasien wamota berhubungan dengan siklus menstruasi. Pasien banyak mengeluhkan bahwa AV muncul sesaat sebelum atau sesudah menstruasi ${ }^{32}$.

Berbeda halnya dengan penelitian oleh Siregar et $\mathrm{al}^{7}$ yang menggunakan uji statistik chi square dan mendapatkan nilai $\mathrm{p}=0,103$ ( $p>0,005$ ) yang menunjukkan tidak terdapat hubungan antara kejadian menstruasi dan AV. Demikian pula dengan penelitian Gonçalves et al $^{15}$ yang menyatakan bahwa prevalensi AV yang diamati ialah pada 61 siswa $(62,2 \%)$. terdapat 42 siswa $(69 \%)$ memiliki tingkat AV I dan 18 (30\%) memiliki tingkat AV II; hanya satu siswa yang diklasifikasikan sebagai kelas III. Prevalensi AV tidak berhubungan secara bermakna dengan jenis kelamin $(\mathrm{p}=0,72)$, riwayat AV dalam keluarga $(\mathrm{p}=0,65)$, rambut berminyak $(\mathrm{p}=0,18)$, kebiasaan merokok ( $\mathrm{p}=0,25)$ atau munculnya AV yang dirasakan sendiri $(p=0,48)$. Keteraturan siklus menstruasi tidak terkait $(\mathrm{p}=0,73)$ dengan munculnya $\mathrm{AV}$.

\section{SIMPULAN}

Menstruasi memengaruhi kemunculan dan keparahan akne vulgaris.

Disarankan untuk melakukan penelitian mengenai keterkaitan dan pengaruh menstruasi terhadap akne vulgaris sehingga dapat memperbaharui informasi terkini. Edukasi kepada masyarakat, khususnya kaum remaja wanita mengenai pengaruh menstruasi terhadap akne vulgaris.

\section{Konflik Kepentingan}

Penulis menyatakan tidak terdapat konflik kepentingan dalam studi ini.

\section{DAFTAR PUSTAKA}

1. Sitohang IBS, Wasitatmadja SM. Akne Vulgaris. In: Menaldi SLS, Bramono K, Indriatmi $\mathrm{W}$, editors. Ilmu Penyakit Kulit dan Kelamin (7th ed). Jakarta: Badan Penerbit FKUI, 2017; p. 288-91.

2. Mizwar M, Kapantow MG, Suling PL. Profil akne vulgaris RSUP Prof. Dr. R. D. Kandou Manado periode 2009-2011 [Skripsi]. Manado: Universitas Sam Ratulangi; 2013.

3. Astuti D. Hubungan antara mestruasi dengan angka kejadian akne vulgaris pada remaja [Skripsi]. Semarang: Universitas Diponegoro; 2011.

4. Sinaga E, Saribanon N, Suprihatin, Sa'adah N, Salamah U, Murti YA, et al. Manajemen Kesehatan Menstruasi. Jakarta: Universitas Nasional, IWWASH. Global One, 2017.

5. Fadhil I, Studi P, Abulyatama U, Studi P, Abulyatama U. Hubungan waktu menstruasi dengan kejadian akne vulgaris pada mahasiswi Kedokteran Abulyatama Aceh [Skripsi]. Aceh: Universitas Abulyatama; 2019.

6. Widiawaty A, Darmani EH, Amelinda. Pengaruh fase menstruasi terhadap derajat akne vulgaris mahasiswi Fakultas Kedokteran Universitas Riau. Media Dermato Venerologica Indonesiana. 2019;46(1):9-12.

7. Siregar EDU, Ramona FSP, Dewi LM. Hubungan antara kelainan siklus menstruasi dengan kejadian akne vulgaris pada santriwati SMA Islam Terpadu Nur Hidayah Kartasura [Skripsi]. Surakarta: Universitas Muhammadiyah Surakarta; 2017.

8. Elmiyati, Fadhil. Hubungan waktu menstruasi dengan kejadian akne vulgaris pada mahasiswi kedokteran Abulyatama Aceh. Prosiding SEMDI-UNAYA (Seminar Nasional Multi Disiplin Ilmu UNAYA), 2019;3(1). 
9. Indrawan N, Kusumastuti AC. Hubungan asupan lemak jenuh dengan kejadian AV. J Nutr Coll. 2013;2(4):578-84.

10. Purwaningdyah RAK, Jusuf NK. Profil penderita AV pada siswa siswi di SMA Shafiyyatul Amaliyyah Medan. EJournal FK USU. 2013;1(1):1-8.

11. Geller L, Rosen J, Frankel A, Goldenberg G. Perimenstrual flare of adult acne. J Clin Aesthet Dermatol. 2014;7(8):30-4.

12. Yazmalar L, Celepkolu T, Batmaz I, Sariyildiz MA, Sula B, Alpayci M, et al. High frequency of fibromyalgia in patients with acne vulgaris. Arch Rheumatol. 2016;31(2):170-5.

13. George RM, Sridharan R. Factors aggravating or precipitating acne in Indian adults: A hospital-based study of 110 cases. Indian J Dermatol. 2018;63(4): 328-31.
14. Dae HS, Byung YK, Seong UM, Dong HL, Mi YY, Nack IK, et al. A multicenter epidemiological study of acne vulgaris in Korea. Int J Dermatol. 2011;50(6): 673-81.

15. Goncalves G, Amado JM, Massa A. The prevalence of acne among a group of Portuguese medical students. J Eur Acad Dermatol Venereol. 2012;26(4): 514-7.

16. Ayudianti P, Indramaya DM. 2014. Faktor Pencetus akne vulgaris (Factors aggravating acne vulgaris ) [Skripsi]. Berkala Ilmu Kesehatan Kulit \& Kelamin. 2014;26(1):41-7.

17. Astuti DW. Hubungan antara menstruasi dengan angka kejadian AV pada remaja [Karya Tulis Strata-1]. Semarang: Universitas Diponegoro; 2011. 